\title{
Species-Specific Therapy of Acute Lymphoid Leukemia
}

D. Pinkel

Forty years ago, Farber and associates described temporary remissions of acute leukemia in children produced by folic acid antagonists [13]. This ignited the hope that this most frequent and always fatal childhood cancer might be curable by drugs. Twenty years ago, Aur and associates completed accession of patients to total therapy study $\mathrm{V}$, the first treatment protocol to result in $50 \%$ cure of acute lymphoid leukemia (ALL) [3]. Their results stand 20 years later (Fig. 1), and have been reproduced throughout the world in many thousands of children [6]. More important, recent national vital statistics of the United States and the United Kingdom indicate a $50 \%$ reduction in childhood leukemia mortality [4, 29]. Further, the cured children generally enjoy a normal life-style without need for medication.

In the past 20 years, efforts have been directed at improving the cure rate of ALL while simplifying curative treatment, reducing its side effects, and improving its availability and accessibility. In a Stohlman Lecture at Wilsede 10 years ago the following statement was made [32]:

- The most significant opportunity for improving the treatment of acute lymphoid leukemia in the past five years has been its biological and clinical classification by immunological cell surface markers. This allows species identification of the leukemia cells, the first step toward developing specific cytocidal or cytostatic therapy.

The University of Texas M.D. Anderson Cancer Center, Dept. of Pediatrics, Houston, Texas 77030 , USA
The purpose of this communication is to review progress in immunophenotypespecific therapy of ALL, to discuss some alternate methods of guiding treatment, and to introduce the notion of genotypespecific chemotherapy of ALL.

\section{A. Immunophenotype-Specific Therapy of $A L L$}

\section{Historical Perspective}

When the first effective drugs were used to treat acute leukemia it became apparent that some cases were more responsive than others [12]. Methotrexate, prednisone, or mercaptopurine were most likely to produce remissions in children with ALL. Adults with ALL were less likely to experience remission. Both children and adults with acute nonlymphoid

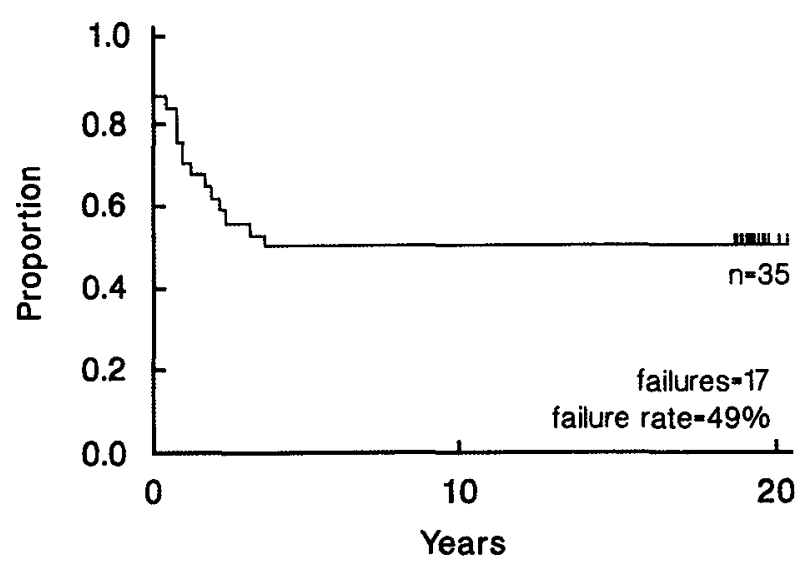

Fig. 1. Event-free survival (EFS) of 35 consecutive children with acute lymphoid leukemia admitted to St. Jude Children's Research Hospital from December 1967 to June 1968. Approximately one-half remain continuously free of leukemia for 20 years and off therapy for 18 years. Update of [3], kindly provided by Gaston Rivera 
leukemia (ANLL) had few remissions with these agents. Some hematologists concluded that chemotherapy was of little use in adult acute leukemia and was perhaps better withheld in ANLL, in children as well as adults.

With the introduction of daunorubicin and cytarabine in the $1960 \mathrm{~s}$ it became apparent that these drugs were highly active in the majority of patients with ANLL, especially when combined [18]. On the other hand, their value in childhood ALL was not so apparent. The concept of species-specific therapy was thus evolved and it became customary to utilize prednisone, vincristine, methotrexate, and mercaptopurine as the primary drugs for ALL, and daunorubicin and cytarabine as the mainstay of treatment of ANLL.

\section{Species-Specific Therapy of T-Cell ALL}

When T-cell ALL was first defined it was noted that children with this disease had short remissions and high mortality compared with children who had non-T ALL [43]. These observations were generally confirmed by others. However, in mice it was demonstrated that cyclophosphamide and cytarabine were more effective in AKR leukemia, a T-cell line, and Sullivan et al. suggested that cytarabine was specifically effective in human T-cell lymphoma/leukemia [42, 47]. A comparative study in children with ALL in remission demonstrated that the cure rate of T-cell ALL approached that of non-T ALL when the T-cell patients received cyclophosphamide and cytarabine in addition to methotrexate and mercaptopurine [26]. On the other hand, the cyclophosphamide and cytarabine provided no curative benefit, only additional toxicity, to children with non-T ALL receiving methotrexate and mercaptopurine. Thus, it became clear that immunophenotype of ALL was important in selecting and scheduling curative drug therapy.
The importance of immunophenotype-specific chemotherapy of T-cell lymphoma/leukemia was confirmed in a recent Pediatric Oncology Group study [1]. With a treatment plan that emphasizes the use of cytarabine, cyclophosphamide, Adriamycin, and teniposide, and excludes systemic methotrexate, actuarial event-free survival for 94 children with T-cell ALL is $71 \%$ at 18 months. Since most relapses of T-cell ALL occur within 18 months this is a meaningful figure.

\section{Species-Specific Therapy of B-Cell ALL}

When B-cell ALL was defined its rapidly fatal course despite chemotherapy was noted and confirmed [15]. However, two reports indicate that distinctive treatment plans emphasizing the use of cyclophosphamide, the most active agent in childhood B-cell lymphoma/ALL, and a concentrated, relatively brief multipledrug program, result in a $40 \%$ cure rate $[14,30]$. A Pediatric Oncology Group study appears to be confirming these observations (Bowman, personal communication).

\section{Species-Specific Therapy} of Non-T Non-B ALL

The question rises whether speciesspecific therapy of subclasses of non- $T$ non-B ALL might be appropriate. As with T-cell ALL and B-cell ALL, the first suggestion of the need for specific therapy is the appearance of an association between immunophenotype and prognosis on a given treatment regimen. Just as T-cell ALL and B-cell ALL demonstrated short remissions and very high mortality in early treatment programs, two immunophenotypic species of non-T non- $B$ ALL have had less favorable courses in more recent studies. First is the "null" or pre-B lymphoid/monocytoid species associated with age less than 1 year, low CALLA antigen, chromosomal translocations involving chromosome 11, band 
Table 1. Species-specific therapy, non-T, non-B ALL, treatment plan

Remission induction -6 weeks

Days 1-28: prednisone, vincristine, asparaginase, triple intrathecal therapy

Days 29-42: mercaptopurine, triple intrathecal therapy

Continuation therapy $-2-2 \frac{1}{2}$ years

Methotrexate weekly, mercaptopurine daily

Periodic triple intrathecal therapy

Periodic pulses of prednisone, vincristine, asparaginase

Periodic intensive therapy - during continuation chemotherapy

Early pre-B Intermediate dosage methotrexate

Early pre-B/monocytoid Intermediate dosage etoposide + cytarabine

Early pre-B/T cell Intermediate dosage methotrexate

Intermediate dosage cyclophosphamide + cytarabine

Pre-B

Intermediate dosage methotrexate + cytarabine

Intermediate dosage cyclophosphamide

The systemically administered mercaptopurine, methotrexate, cytarabine, cyclophosphamide, and etoposide are given in maximum tolerated dosage, using clinical status, absolute phagocyte count, and mean corpuscular volume as guides

q 23, presence of myeloid antigens, and monocytoid characteristics by electron microscopy and cell culture [23]. Second is pre-B ALL, which demonstrates cytoplasmic immunoglobulin and is sometimes associated with a $t(1 ; 19)$ chromosomal translocation [35]. A species of T-cell ALL that demonstrates CALLA antigen is reported to have a cure rate between that of T-cell ALL and common ALL on traditional therapy [9].

At UT MD Anderson Cancer Center a pilot protocol was designed and initiated for children newly diagnosed with non- $T$ non-B ALL that provides different periodic consolidation therapy for four different species: common (early pre-B CALLA +), null (early pre-B lymphoid/ monocytoid), early pre-B CALLA + and thymic antigen + , and pre-B (Table 1). Each of the four regimens utilizes periodic consolidation drugs and drug schedules that are currently believed to be most effective for these specific subclasses, while retaining a core of conventional continuation therapy with daily mercaptopurine, weekly methotrexate, pulses of prednisone, vincristine and asparaginase, and periodic triple-intrathecal therapy.
Early results suggest the feasibility of this pilot protocol. Of 26 consecutive children registered in the past 18 months, 24 developed complete remission. None have experienced relapse yet.

In summary, immunophenotypespecific selection and scheduling of chemotherapy has proven to be important for increasing the cure rate of T-cell and B-cell ALL. It may also be applicable to upgrading the curability of null ALL and pre-B ALL as well. Almost as important, immunophenotype-specific therapy allows one to exclude nonessential antineoplastic drugs from the combination chemotherapy regimens of ALL, thus avoiding unnecessary immediate and long-term toxic hazards. The prime example is hyperdiploid common ALL, which is highly curable with methotrexate and mercaptopurine continuation chemotherapy [6, 49]. There is no evidence that addition of anthracyclines or alkylating agents improves its cure rate [5]. Therefore, there is no reason to expose these highly vulnerable pre-school children to the risks of anthracycline cardiomyopathy or cyclophosphamide-induced bladder carcinoma [27, 31]. 


\section{B. Selection and Scheduling Chemo- therapy by "Prognostic Factors"}

It was recognized decades ago that initial white blood cell count was predictive of response to leukemia chemotherapy [51]. Subsequently, other factors were identified and the term "high risk for treatment failure" was coined for patients with ALL who had such features [2]. It was suggested that more extensive remission induction chemotherapy be administered to such patients. Since then, terms such as "standard risk," "low risk," and "high risk" have become popular to define prognostic categories of patients with ALL and to select and schedule their chemotherapy [46]. In general, patients with "high-risk" ALL are given more drugs in higher dosage, particularly such agents as anthracyclines, alkylating compounds, and epipodophyllotoxins. Patients with "low-risk" ALL are given fewer drugs in lesser dosage, primarily corticosteroid, vinca alkaloid, and antimetabolites. In some treatment programs the decision to use cranial irradiation is based on "risk group" [46].

The problem with using prognostic factors to select therapy is that they are artifacts of data analysis and treatment $[33,34]$. More aggressive and rapidly proliferating ALL tends to relapse early; less aggressive and slowly proliferating ALL tends to relapse late. When complete remission duration is used as the criterion for assessing prognostic factors undue weight is given to features associated with remission duration rather than to the true measure of efficacy of therapy, cure, as represented by the plateau of continuous complete remission. This problem with the use of prognostic factors could be corrected by using cure rate instead of remission duration to calculate prognostic variants.

However, the more important issue is treatment artifact. All leukemias are fatal when untreated. Survival and cure depend on the administration of appropriate drugs in appropriate schedules. For example, when T-cell ALL was treated with conventional non-T ALL chemotherapy it had a rapidly fatal course in most patients [26]. Features associated with T-cell ALL such as thymic mass, male sex, high white cell count, and older age were calculated to be "highrisk" or "bad-prognosis" factors. With appropriate chemotherapy of T-cell ALL these "risk factors" largely disappear.

In conclusion, there is no evidence that one type of ALL is inherently more lethal than another. All are equally lethal. Cure of ALL is solely a matter of developing and selecting the appropriate drug regimens for each specific type of ALL. The use of prognostic factors to guide leukemia therapy should be abandoned because it is based on artifacts and can give rise to erroneous conclusions.

\section{All-Inclusive Multiple-Drug Chemotherapy for All ALL}

Another method of selecting therapy for ALL is to avoid selection, but to give all patients all active antineoplastic drugs without regard to immunophenotypic species [37]. This approach carries multiple problems.

Unlike antibiotics, most antineoplastic drugs have overlapping short-term side effects. Administration of one drug usually interferes with the dosage of the other. If minimally effective or noneffective drugs are included in a combination, the dosage of the more effective drugs generally must be reduced. If numerous drugs with overlapping toxicities are utilized it is possible that the most effective drug or drugs may be given at minimally effective dosages and their benefit compromised or lost. Exposure to suboptimal dosage of drugs is an important mechanism of developing resistant cell lines in vitro and could be a mechanism in vivo.

In some all-inclusive multiple-drug regimens, drugs or drug combinations are alternated in order to minimize reduction of drug dosages [37]. The problem with this technique is that the leukemia, in effect, may be untreated or 
minimally treated during those intervals when drugs of minimal or no efficacy for that particular leukemia are being given. One might postulate the possibility of resurgence of leukemia cell proliferation during such periods of minimally effective or noneffective therapy.

A theoretical objection to the use of multiple drugs is the possibility of antagonistic interactions that might subtract from the efficacy of a given drug [21]. Little is known about subtractive drug interactions in human cancer chemotherapy. One would assume that the risk of such interactions would increase geometrically with linear increase in the number of drugs administered.

A major concern of cancer chemotherapy in children is the prospect of serious long-term sequelae. As noted previously, of special concern are the anthracyclines and the alkylating agents. In one study of children surviving ALL, $55 \%$ of those who had received doxorubicin demonstrated abnormal left ventricular function and/or afterload by echocardiography [27]. Cyclophosphamide not only produces sterility but carries a $10 \%$ risk of urinary bladder carcinoma 12 years later [31]. To exemplify this concern, it is known that children with hyperdiploid common ALL have a $70 \%$ or greater cure rate without alkylating agents or anthracyclines $[6,49]$. The only comparative studies reported have failed to demonstrate that these agents contribute to the cure of common ALL in first remission [5]. For these reasons they should be avoided in children with hyperdiploid common ALL who are newly diagnosed or in first remission. The same can be said for any drug with demonstrated serious sequelae that has failed comparative testing for its value in contributing to the cure of a specific type of ALL.

A final objection to the all-inclusive multiple-drug chemotherapy approach is its excessive complexity and cost. This tends to limit the availability and accessibility of curative leukemia therapy to more privileged patients and more privi- leged nations. The objective of leukemia therapy is to reduce national and world leukemia mortality, not only that of wellfinanced medical centers.

\section{Genotype-Specific Therapy of ALL}

\section{Acute Leukemias Are Genetic Disorders of Hematopoietic Cells}

The most important advance in leukemia therapy in the past 10 years is the renewed realization that leukemias are genetic disorders of hematopoiesis $[34,38$, 41]. Their abnormal morphology, immunophenotype, growth, and function are all reflections of their genetic abnormalities. This opens a pathway of drug therapy specific to their genetic properties, aimed at converting their genetic advantages to liabilities.

The evidence that acute leukemias are genetic disorders is convincing [34]. The risk of leukemia is increased in certain constitutional genetic disorders such as Down's, Fanconi's, and Bloom's syndromes and in persons exposed to mutagens such as ionizing irradiation. The morphology of leukemia cells tends to be disorderly and asynchronous, reflecting disordered genetic expression. Chromosome morphology is disturbed in most acute leukemias [41]. Nonrandom chromosome abnormalities are associated with specific types of acute leukemia, such as the $t(1 ; 19)$ translocation in pre-B ALL, the $t(8 ; 14)$ in B-cell ALL, and the $t(15 ; 17)$ in acute promyeloid leukemia $[7$, $35,38]$.

Immunophenotypic and molecular genetic disorders are also prevalent in acute leukemias $[20,34,45]$. Some ALLs express surface antigens characteristic of B-cell and T-cell lineage simultaneously. Early pre-B-(common) ALL often demonstrates rearrangement of genes encoding the $\mathrm{T}$-cell receptor while $\mathrm{T}$-cell ALL may show gene rearrangement for immunoglobulins. It is now obvious that ALLs do not have true B-lymphocyte or T-lymphocyte lineage. Their genetic and phenotypic immunological markers are 
merely further reflections of their underlying genetic disorders. ALL is a genetic, not an immunological, disease.

The most recent evidence that acute leukemias are genetic disorders is the discovery of overexpression of certain oncogenes in some cases, for example, c-myc in B-cell ALL and c-sis in acute megakaryocytic leukemia $[7,48]$.

\section{Chemotherapy May Cure Acute} Leukemia by Genetic Mechanisms Although chemotherapy appears to induce remissions of acute leukemia by direct cytolytic effects, it is possible to speculate that cures result from genetic alteration during chemotherapy [34]. Curative drugs such as methotrexate, cytarabine, cyclophosphamide, daunorubicin, and etoposide alter DNA structure as well as synthesis, while drugs without direct effect on DNA such as prednisone, vincristine, and asparaginase do not appear to be curative.

Secondly, curative chemotherapy eliminates genetically disturbed hematopoiesis but spares the capacity for genetically normal hematopoiesis [34]. The best example is the lymphoblastic and lymphocytic hyperplasia noted in the bone marrow of children with ALL after cessation of chemotherapy. Sometimes the frequency of CALLA+lymphoblasts in these children is sufficient to cause confusion with relapse.

Finally, the curative capacity of chemotherapy is strongly related to the genotype of the leukemia [34, 41]. For example, methotrexate and mercaptopurine is a highly curative drug combination in hyperdiploid common ALL, but not in common ALL with a $t(9 ; 22)$ translocation $[45,49]$. Daunorubicin and cytarabine is more often curative in acute myeloid leukemia (AML) with a $t(8 ; 21)$ translocation than in AML without this translocation [41]. It is possible that leukemia chemotherapy, when it is curative, is more specific in affecting the genetic mechanism or genetic survival of leukemia strains than we have recognized.
III. Rationale for Genotype-Specific Therapy of ALL

The basis for attempting to target chemotherapy of ALL to its genotypic characteristics is severalfold. First is the convincing evidence that acute leukemias are genetic disorders of hematopoietic cells [34]. Their morphology, immunological markers, growth rate, and other phenotypic properties are reflections of their specific genetic disorders.

Secondly, genetic properties are the most significant variables in curability by a given therapeutic regimen $[6,49]$. This indicates that therapeutic regimens should be varied in accordance with the genetic properties of the leukemias in order to achieve optimal cure rates. For example, common ALL with a $t(9 ; 22)$ translocation needs to be treated differently than common ALL with hyperdiploidy in order that the $t(9 ; 22)$ variety becomes as curable as the hyperdiploid type.

Thirdly, the current practices of altering chemotherapy regimens in accordance with morphology (ALL vs. ANLL), immunophenotype ( $T$ cell vs. B cell), and aggressiveness (white blood cell count) in fact do recognize genotypic properties because all these features reflect the genetic disorders. It would appear more rational to aim treatment directly at the genetic disorders that underly these features as we learn to define these disorders more precisely.

Finally, as noted above, there is reason to speculate that chemotherapy produces remissions by direct cytotoxicity but cures by genetic alteration.

\section{Relationships Between Genotype and Drug Efficacy in ALL}

The relationships between the known genotypes of acute lymphoid leukemias and what appear to be the most effective drugs and drug combinations for curing them are summarized in Table 2. The data are yet fragmentary, only the beginning of an approach at targeting drug therapy to the genetic disorders of the 
Table 2. Genotype and drug curability, acute lymphoid leukemia

\begin{tabular}{|c|c|c|c|c|}
\hline Phenotype & $\begin{array}{l}\text { Chromosomal } \\
\text { rearrangements }\end{array}$ & Involved genes & Curative drugs & References \\
\hline Common & $\begin{array}{l}\text { Hyperdiploidy } \\
\mathrm{t}(9 ; 22)(\mathrm{q} 34 ; \mathrm{q} 11)\end{array}$ & $\begin{array}{l}? \\
c-a b l, b c r\end{array}$ & $\begin{array}{l}\text { Methotrexate+ } \\
\text { mercaptopurine } \\
?\end{array}$ & $\begin{array}{l}{[6,49]} \\
{[6,39,45]}\end{array}$ \\
\hline Pre-B & $t(1 ; 19)(q 23 ; p 13)$ & Insulin receptor $\alpha$ & $\begin{array}{l}\text { Methotrexate+ } \\
\text { cytarabine (?) }\end{array}$ & {$[50]$} \\
\hline \multirow[t]{2}{*}{$\mathrm{T}$ cell } & $\begin{array}{l}\mathrm{t}(10 ; 14)(\mathrm{q} 24 ; \mathrm{q} 11) \\
\mathrm{t}(11 ; 14)(\mathrm{p} 13 ; \mathrm{q} 11) \\
\mathrm{t}(8 ; 14)(\mathrm{q} 24 ; \mathrm{q} 11) \\
\mathrm{t}(1 ; 14)(\mathrm{p} 32 ; \mathrm{q} 11) \\
\text { inv }(14)(\mathrm{q} 11 ; \mathrm{q} 32)\end{array}$ & $\begin{array}{l}\operatorname{tcr} \alpha, T d T(?) \\
\operatorname{tcr} \alpha, W T(?) \\
\operatorname{tcr} \alpha, c-m y c \\
\operatorname{tcr} \alpha \\
\operatorname{tcr} \alpha, \operatorname{Ig} \mu\end{array}$ & $\begin{array}{l}\text { Cytarabine }+ \\
\text { cyclophosphamide }\end{array}$ & $\begin{array}{l}{[8,10,11]} \\
{[16,25,26]}\end{array}$ \\
\hline & $\begin{array}{l}\mathrm{t}(1 ; 7)(\mathrm{p} 32 ; \mathrm{q} 32) \\
\mathrm{t}(2 ; 7)(\mathrm{p} 21 ; \mathrm{q} 36) \\
\mathrm{t}(6 ; 7)(\mathrm{p} 21 ; \mathrm{q} 36)\end{array}$ & $\operatorname{ter} \beta$ & & {$[36]$} \\
\hline B cell & $\begin{array}{l}\mathrm{t}(8 ; 14)(\mathrm{q} 24 ; \mathrm{q} 32) \\
\mathrm{t}(8 ; 22)(\mathrm{q} 24 ; \mathrm{q} 11) \\
\mathrm{t}(2 ; 8)(\mathrm{p} 11 ; \mathrm{q} 24)\end{array}$ & $\begin{array}{l}\operatorname{Ig} \mu, \mathrm{c}-m y c \\
\operatorname{Ig} \lambda, \mathrm{c}-m y c \\
\operatorname{Ig} \kappa, \mathrm{c}-m y c\end{array}$ & Cyclophosphamide & {$[7,14,30]$} \\
\hline \multirow[t]{3}{*}{ Null } & $\mathrm{t}(4 ; 11)(\mathrm{q} 21 ; \mathrm{q} 23)$ & $\begin{array}{l}\text { IP-10 } \\
\text { c-ets-1 (?) }\end{array}$ & $\begin{array}{l}\text { Epipodophyl- } \\
\text { lotoxins }\end{array}$ & {$[17,19,23,28]$} \\
\hline & $\mathrm{t}(1 ; 2 ; 11)(\mathrm{p} 36 ; \mathrm{p} 13 ; \mathrm{q} 21)$ & $\begin{array}{l}\text { c-fgr (?) } \\
\text { c-src-2 (?) } \\
\text { c-ets-1 (?) }\end{array}$ & & [40] \\
\hline & $\begin{array}{l}\mathrm{t}(11 ; 19)(\mathrm{q} 23 ; \mathrm{p} 13) \\
\mathrm{t}(1 ; 11)(\mathrm{p} 32 ; \mathrm{q} 23) \\
\mathrm{t}(10 ; 11)(\mathrm{p} 15 ; \mathrm{q} 23)\end{array}$ & c-ets-1 (?) & & {$[22]$} \\
\hline
\end{tabular}

Many of the molecular genetic and drug data are unconfirmed or speculative

leukemias rather than to the phenotypic features that reflect the genetic disorders. As breakpoints of chromosomal translocations are defined in molecular terms and it becomes possible to classify leukemias as specific molecular genetic disorders it is to be expected that leukemias without apparent chromosomal rearrangements will be shown to have rearrangements of genes similar to those that do have the chromosomal changes. This has already been described in adult-type chronic myeloid leukemia where cases without the typical $t(9 ; 22)$ translocation have the same $b c r-a b l$ rearrangement that occurs in those with the translocation [24, 44]. As the acute leukemias become better defined in molecular genetic terms it seems plausi- ble that genotype-specific therapy will become more apparent and feasible.

\section{E. Summary}

In the past 10 years immunophenotyping of ALL has been demonstrated to be useful for selecting and scheduling chemotherapy. Different drug regimens are now used for T-cell and B-cell ALL than for non-T non-B ALL with the result that survival and cure of T-cell and B-cell ALL have been considerably improved. The use of different drug regimens for different immunophenotypic varieties of non- $T$ non-B ALL is being tested. 
"Prognostic factors" of ALL are artifacts of data analysis and treatment and should no longer be used for guiding treatment. The administration of all-inclusive multiple-drug therapy to all patients with ALL regardless of species should also be abandoned. Minimally effective drugs can interfere with dosage and continuity of more effective drugs, and can result in side effects and sequelae that increase the mortality and morbidity of treatment.

Since acute leukemias are genetic disorders of hematopoiesis the future direction of leukemic therapy is toward genetic targeting.

\section{References}

1. Amylon $M$, Murphy $S$, Pullen $J$ et al. (1988) Treatment of lymphoid malignancies according to immune phenotype: Preliminary results in T-cell disease (Abstr). Proc Am Soc Clin Oncol 7:225

2. Aur RJA, Simone JV, Pratt $\mathrm{CB}$ et al. (1971) Successful remission induction in children with acute lymphocytic leukemia at high risk for treatment failure. Cancer 27:1332-1336

3. Aur RJA, Simone JV, Hustu HO et al. (1971) Central nervous system therapy and combination chemotherapy of childhood lymphocytic leukemia. Blood 37:272-281

4. Birch JM, Marsden HB, Jones PH et al. (1988) Improvements in survival from childhood cancer: results of a population based survey over 30 years. $\mathrm{Br}$ Med J 296: $1372-1376$

5. Camitta BM, Pinkel D, Thatcher G et al. (1980) Failure of early intensive chemotherapy to improve prognosis in childhood acute lymphocytic leukemia. Med Pediatr Oncol 8:383-389

6. Crist WM, Furman W, Strother D et al. (1987) Acute lymphocytic leukemia in childhood: Immunologic marker, cytogenetic, and molecular studies. South Med J 80:841-847

7. Croce CM (1986) Chromosome translocations and human cancer. Cancer Res 46: 6019-6023

8. Denny CT, Hollis GF, Hecht $F$ et al. (1986) Common mechanism of chromo- some inversion in B- and T-cell tumors: Relevance to lymphoid development. Science 234: 197-200

9. Dowell BL, Borowitz MJ, Boyett JM et al. (1987) Immunologic and clinicopathologic features of common acute lymphoblastic leukemia antigen-positive childhood $\mathrm{T}$ cell leukemia. Cancer 59:2020-2026

10. Dube ID, Raimondi SC, Pi D et al. (1986) A new translocation, $t(10 ; 14)(q 24 ; q 11)$, in $T$ cell neoplasia. Blood 67:1181-1184

11. Erikson J, Finger L, Sun L et al. (1986) Deregulation of c-myc by translocation of the $\alpha$-locus of the T-cell receptor in T-cell leukemias. Science 232:884-886

12. Farber S, Toch R, Sears EM, Pinkel D (1956) Advances in chemotherapy of cancer in man. Adv Cancer Res 4:1-71

13. Farber S, Diamond LK, Mercer RD et al. (1948) Temporary remissions in acute leukemia in children produced by folic acid antagonist, 4-aminopteroyl-glutamic acid (aminopterin). N Engl J Med 238: 787-793

14. Feickert HJ, Göbel U, Ludwig W et al. (1987) Childhood acute lymphoblastic leukemia of B-cell type: Trials ALL-BFM 81 and ALL-BFM 83 (Abstr). Proc Am Soc Clin Oncol 6:149

15. Flandrin G, Brouet JC, Daniel MT et al. (1975) Acute leukemia with Burkitt's tumor cells: A study of six cases with special reference to lymphocyte surface markers. Blood 45: 183-188

16. Finger LR, Harvey RC, Moore RC et al. (1986) A common mechanism of chromosomal translocation in T- and B-cell neoplasia. Science 234:982-985

17. Frankel LS, Ochs J, Shuster J et al. (1987) Pilot protocol improves remissions for infant leukemia and provides detailed laboratory characterization (Abstr). Proc Am Soc Clin Oncol 6:161

18. Gale RP (1979) Advances in the treatment of acute myelogenous leukemia. $N$ Engl $J$ Med 300:1189-1199

19. Goyns MH, Hann IM, Stewart J et al. (1987) The c-ets-1 proto-oncogene is rearranged in some cases of acute lymphoblastic leukaemia. Br J Cancer 56:611-613

20. Hurwitz CA, Loken MR, Graham ML, et al. (1988) Asynchronous antigen expression in B lineage acute lymphoblastic leukemia. Blood 72:299-307

21. Jolivet J, Cole D, Holcenberg JS et al. (1984) L-asparaginase (L-ASP) antagonism of methotrexate (MTX) cytotoxicity: An alternative explanation (Abstr). Pro- 
ceedings of the American Association for Cancer Research 25: 309

22. Kaneko Y, Maseki N, Takasaki $\mathrm{N}$ et al. (1986) Clinical and hematologic characteristics in acute leukemia with 11q23 translocations. Blood 67:484-491

23. Katz F, Malcolm S, Gibbons B et al (1988) Cellular and molecular studies on infant null acute lymphoblastic leukemia. Blood 71:1438-1447

24. Kurzrock R, Blick MB, Talpaz $M$ et al. (1986) Rearrangement in the breakpoint cluster region and the clinical course in Philadelphia-negative chronic myelogenous leukemia. Ann Intern Med 105:673679

25. Lampert F, Harbott J, Ritterbach J et al. (1988) T-cell acute childhood lymphoblastic leukemia with chromosome 14q11 anomaly: a morphologic, immunologic, and cytogenetic analysis of 10 patients. Blut 56:117-123

26. Lauer SJ, Pinkel D, Buchanan GR et al. (1987) Cytosine arabinoside/cyclophosphamide pulses during continuation therapy for childhood acute lymphoblastic leukemia. Cancer 60:2366-2371

27. Lipshultz SE, Colan SD, Sanders SP et al. (1987) Late cardiac effects of doxorubicin in childhood acute lymphoblastic leukemia (ALL) (Abstr). Proceedings of the American Society of Hematology, $234 \mathrm{a}$

28. Luster AD, Jhanwar SC, Chaganti RSK et al. (1987) Interferon-inducible gene maps to a chromosomal band associated with a $(4 ; 11)$ translocation in acute leukemia cells. Proc Natl Acad Sci, USA 84:2868-2871

29. Miller RW, McKay FW (1984) Decline in US childhood cancer mortality 1950 through 1980. JAMA 251:1567-1570

30. Patte C, Philip T, Rodary C et al. (1986) Improved survival rate in children with Stage III and IV B cell non-Hodgkin's lymphoma and leukemia using multiagent chemotherapy: Results of a study of 114 children from the French Pediatric Oncology Society. J Clin Oncol 4:12191226

31. Pedersen-Bjergaard J, Ersboll J, Hansen VL et al. (1988) Carcinoma of the urinary bladder after treatment with cyclophosphamide for non-Hodgkin's lymphoma. N Engl J Med 318: 1028-1032

32. Pinkel D (1979) Treatment of childhood acute lymphocytic leukemia. Modern Trends in Human Leukemia III. R Neth,
RC Gallo, P-H Hofschneider and $\mathrm{K}$ Mannweiler (eds). pp 25-33. New York

33. Pinkel D (1985) Current issues in the management of children with acute lymphocytic leukaemia. Postgrad Med J 61:93-102

34. Pinkel D (1987) Curing children of leukemia. Cancer 59:1683-1691

35. Pui C-H, Williams DL, Kalwinsky DK et al. (1986) Cytogenetic features and serum lactic dehydrogenase level predict a poor treatment outcome for children with pre-B-cell leukemia. Blood 67:1688-1692

36. Raimondi SC, Pui CH, Behm FG et al. (1987) 7q32-q36 Translocations in childhood $\mathrm{T}$ cell leukemia: Cytogenetic evidence for involvement of the T cell receptor $\beta$-chain gene. Blood 69:131-134

37. Rivera GK, Mauer AM (1987) Controversies in the management of childhood acute lymphoblastic leukemia: treatment intensification, CNS leukemia, and prognostic factors. Semin Hematol 24: 12-26

38. Rowley JD (1979) Chromosome abnormalities in leukemia. Modern Trends in Human Leukemia III. R Neth, RC Gallo, $\mathrm{P}-\mathrm{H}$ Hofschneider and $\mathrm{K}$ Mannweiller (eds.). pp 43-52. New York

39. Rubin CM, Carrino JJ, Dickler MN et al. (1988) Heterogeneity of genomic fusion of BCR and ABL in Philadelphia chromosome-positive acute lymphoblastic leukemia. Proc Natl Acad Sci USA 85:2795-2799

40. Sansone R, Strigini $P$ (1988) Infantile leukemia with a new chromosomal rearrangement involving 11q. Cancer Genet Cytogenet 32: 293-294

41. Sandberg AA (1986) The chromosomes in human leukemia. Semin Hematol 23: $201-217$

42. Schabel FM Jr, Skipper HE, Trader MW et al. (1974) Combination chemotherapy for spontaneous AKR lymphoma. Cancer Chemotherapy Reports 4:53-70

43. Sen L, Borella L (1975) Clinical importance of lymphoblasts with $T$ markers in childhood acute leukemia. N Engl J Med 292: 828-832

44. Stam K, Heisterkamp N, Grosveld G et al. (1985) Evidence of a new chimeric bcr/c-abl mRNA in patients with chronic myelocytic leukemia and the Philadelphia chromosome. N Engl J Med 313:1429-1433

45. Stass SA, Mirro J Jr (1986) Lineage heterogeneity in acute leukaemia: Acute mixed-lineage leukaemia and lineage switch. Clin Haematol 15:811-827 
46. Steinherz PG, Gaynon P, Miller DR et al. (1986) Improved disease-free survival of children with acute lymphoblastic leukemia at high risk for early relapse with the New York regimen - A new intensive therapy protocol: A report from the Childrens Cancer Study Group. J Clin Oncol 4: 744-752

47. Sullivan MP, Ramirez I (1982) Contribution of cytosar to $\mathrm{T}$-antigen positive lymphoid disease control in children given 2nd generation $\mathrm{LSA}_{2} \mathrm{~L}_{2}$ therapy. Proc Am Assoc Cancer Res 23:114

48. Sunami S, Fuse A, Simizu B et al. (1987) The c-sis gene expression in cells from a patient with acute megakaryoblastic leukemia and Down's Syndrome. Blood 70:368-371

49. Williams DL, Tsiatis A, Brodeur GM et al. (1982) Prognostic importance of chromosome number in 136 untreated children with acute lymphoblastic leukemia. Blood 60:864-871

50. Yang-Feng TL, Francke U, Ullrich A (1985) Gene for human insulin receptor: Localization to site on chromosome 19 involved in pre-B-cell leukemia. Science 228: 728-730

51. Zuelzer WW, Flatz G (1960) Acute childhood leukemia: A ten-year study, Am J Dis Child 100: 886-907 